\title{
Human Serum from Kidney Cancer Patients Analyzed with a New Sensitive Fast Liquid Differential Scanning Calorimetry Sensor
}

\author{
R. Splinter $^{1}$, A.W. van Herwaarden ${ }^{1}$, S. Pastorekova ${ }^{2}$ \\ ${ }^{1}$ Xensor Integration, Distributieweg 28, 2645 EJ Delfgauw, The Netherlands, \\ rs@xensor.nl \\ 2 Institute of Virology, Slovak Academy of Sciences, Department of Molecular Medicine, \\ Dubravska cesta 9, 84505 Bratislava, Slovak Republic
}

\begin{abstract}
Differential Scanning Calorimetry is being investigated as an analytical tool to detect cancer and other diseases by measuring the heat induced protein denaturation in blood plasma. This paper presents a much faster alternative method by using chip-based Fast Differential Scanning Calorimetry. Compared to standard Differential Scanning Calorimetry Fast Differential Scanning Calorimetry is able to reduce measurement time from hours to seconds. The latest development, a more sensitive chip has been tested with healthy control blood serum and blood serum from kidney cancer patients. Clear differences between the control serum and the serum from the cancer patients are found.
\end{abstract}

Key words: Fast Liquid DSC, Kidney cancer, serum, Flash DSC1, DSC

\section{Introduction}

Differential Scanning Calorimetry (DSC) is an analytical technique in which a sample and reference material are placed in small pans and are heated up at a constant rate, while the power which is necessary to heat up the pans is monitored. The result of the measurement is a plot (thermogram) of the power difference between the sample and reference pan as a function of temperature. The typical measurement rate of DSC is about $1{ }^{\circ} \mathrm{C} / \mathrm{min}$. A faster method is the chip based Fast DSC. With Fast DSC the sample is not placed in a pan, but is directly placed on the membrane of a chip and thus avoiding large thermal time constants. Fast DSC typically works with a measurement rate between 1 and $20,000{ }^{\circ} \mathrm{C} / \mathrm{s}$. Figure 1 shows a Fast DSC measurement of the melting of the metal indium.

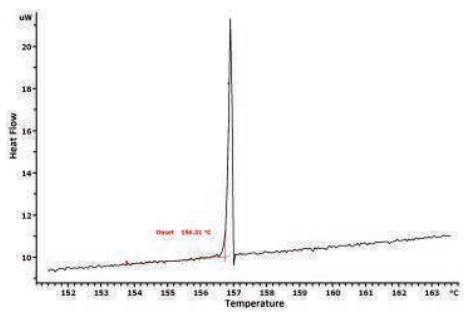

Fig. 1. Fast DSC measurement of an indium sample. The large endothermic peak shows the melting of the metal at the onset temperature of the peak at $156.3^{\circ} \mathrm{C}$.
Recent publications show that Differential Scanning Calorimetry is being investigated as an analytical tool to detect cancer and other diseases by measuring the heat induced protein denaturation (melting of proteins) in blood plasma [1-3]. These publications show that a difference is measured between plasma of healthy individuals and plasma of (cancer) patients. Due to large thermal time constants it takes about 1.5 hours to perform a single measurement with standard DSC.

To reduce measurement time we introduced in 2013 a chip-based liquid sensor [4-5] which can be used in combination with the Flash DSC1 from Mettler Toledo [6] (Figure 2). This Fast Liquid Differential Scanning Calorimetry (FLDSC) sensor is able to reach temperature scan rates as high as $1000{ }^{\circ} \mathrm{C} / \mathrm{s}$ while protein denaturation still could be measured up to 400 ${ }^{\circ} \mathrm{C} / \mathrm{s}$. These high temperature scan rates reduce measurement times from 1.5 hours with standard DSC to less than a single second with the FLDSC sensor. However, the sensitivity of this sensor was not high enough to accurately see the small differences in the FLDSC thermogram between measurements of serum from healthy individuals and serum from cancer patients. To increase the sensitivity we redesigned the chip with a larger heating area and with an increased number of thermocouples. This new more sensitive Fast 
DSC liquid sensor has been tested with human serum from healthy individuals and with serum from kidney cancer patients.

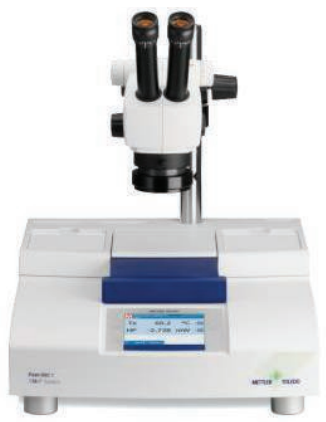

Fig. 2. Flash DSC1 from Mettler Toledo.

\section{Device description}

The FLDSC sensor is based on Fast DSC sensor for the Flash DSC1. The standard sensor for the Flash DSC1 is not suitable for measuring liquids because it is an open chip and any liquid placed on the sensor will evaporate during a measurement. Therefore we designed a cover made from the material Topas. This cover is glued on top of the sensor in such a way that two liquid chambers are created. Figure 3 shows the standard Fast DSC sensor and the adjusted liquid sensor. In the cover are four small holes with serves as inand outlets for the liquid chambers, see figure 4. Topas is chemical resistant and has its $\mathrm{Tg}$ at $170{ }^{\circ} \mathrm{C}$, so the cover does not interfere with the measurements that go up to $150{ }^{\circ} \mathrm{C}$.

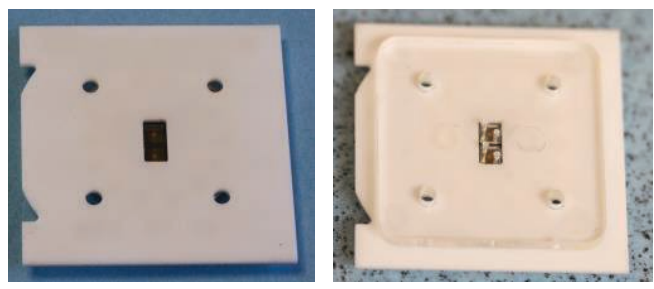

Fig. 3. (left) Standard Fast DSC sensor. (right) Adjusted Fast DSC sensor with a Topas cover glued on top of the ceramic baseplate.

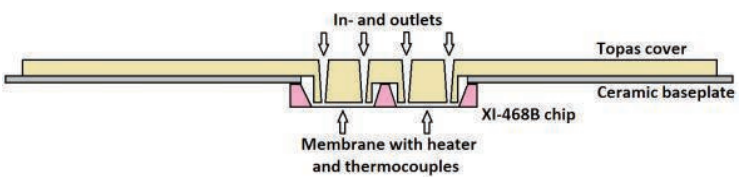

Fig. 4. Cross-section of the FLDSC sensor (not to scale), with Topas cover, Ceramic baseplate and the XI-468B chip.

The total capacity of one liquid chamber is about $1 \mu \mathrm{l}$, but only the $25 \mathrm{nl}$ liquid just on top of the heater is heated up during a measurement, while the rest of the liquid remains at room temperature.

The new FLDSC sensor makes use of the XI$468 \mathrm{~B}$ chip, this chip has in comparison to the XI-400 chip 32 thermocouples instead of 8 , and a heater with a diameter of $0.8 \mathrm{~mm}$ instead of $0.5 \mathrm{~mm}$. Measurements with bovine serum show an increased sensitivity of 7 times of the XI-468B chip based FLDSC sensor compared to the XI-400 chip based FLDSC sensor. Figure 5 shows both chips and table 1 gives an overview between the differences of an FLDSC sensor based on the XI-400 chip and on the XI468B chip.
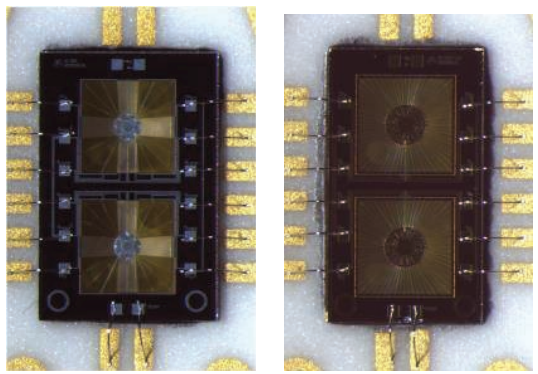

Fig. 5. (left) XI-400 chip with two membranes. In the middle of the membranes is the hotspot with a diameter of $0.5 \mathrm{~mm}$ and 8 thermocouples. (right) XI$468 \mathrm{~B}$ chip with a hotspot with a diameter of $0.8 \mathrm{~mm}$ and 32 thermocouples.

Tab. 1: Comparison of FLDSC measurement of bovine serum measured with FLDSC sensors based on the XI-400 and the XI-468B.

\begin{tabular}{|c|c|c|}
\hline Bovine serum & $\mathrm{XI}-400$ & $\mathrm{XI}-468 \mathrm{~B}$ \\
\hline $\begin{array}{c}\text { Optimum } \\
\text { Scan rate }\end{array}$ & $400^{\circ} \mathrm{C} / \mathrm{s}$ & $103^{\circ} \mathrm{C} / \mathrm{s}$ \\
\hline Integral & $5.6 \mu \mathrm{J}$ & $39.7 \mu \mathrm{J}$ \\
\hline $\begin{array}{c}\text { Signal/Noise } \\
\text { Ratio }\end{array}$ & 62 & 327 \\
\hline
\end{tabular}

\section{Materials and methods}

All measurements were performed with the same temperature program; from $34{ }^{\circ} \mathrm{C}$ to 117 ${ }^{\circ} \mathrm{C}$ with a temperature scan rate of $103^{\circ} \mathrm{C} / \mathrm{s}$. Blood serum samples were obtained from the Institute of virology of the Slovak Academy of Sciences in Bratislava. Healthy control serum samples and serum samples originating from kidney cancer patients who were diagnosed with CCRCC grade 2-3 and stage pT1 p Nx $\mathrm{pMx}$ were obtained. The total protein of the serum samples was measured and all results were normalized to a total protein of $26.7 \mu \mathrm{g} / \mu \mathrm{l}$. 
To prevent aggregation of the serum in the chip during the measurement a 3 M 3-(1-Pyridinio)1-propanesulfonate (NDSB) solution [7] was added to all serum samples to a final concentration of $1 \mathrm{M}$ NDSB. As reference demi water was used which was mixed with NDSB to a final concentration of $1 \mathrm{M}$. All measurements were performed with a single FLDSC sensor which was cleaned by flushing the sensor with demi water between the measurements.

\section{Results and discussion}

When blood plasma is measured with DSC, two main endothermic peaks can be distinguished, which originate from the proteins Albumin and Immunoglobulin. A much smaller endothermic peak originating from the protein Fibrinogen is also measured [2]. Blood serum is basically the same as blood plasma except that the clotting protein Fibrinogen is removed during the clotting process when blood serum is made from blood plasma. In our previous experiments our results for blood plasma and blood serum were similar. Because of better availability of blood serum samples compared to blood plasma samples we chose to perform the experiments with serum samples.

A typical FLDSC thermogram of a measurement of serum from a healthy person is shown in figure 6 . This curve is curve fitted with two Gaussian peaks, representing the proteins Albumin and Immunoglobulin, and this gives a good fit. The result is comparable to DSC measurements with blood plasma done by others [1-2], and to our previous results performed with FLDSC sensors that are based on the XI-400 chip [8]. Figure 7 shows thermograms of FLDSC measurements of healthy control serum and serum from cancer patients. Table 2 gives an overview of these results. The control serum shows a larger peak from the protein Albumin and a smaller peak from the protein Immunoglobulin. The kidney cancer patient serum sample 2 shows two peaks with almost the same height. In sample 1 the Albumin peak is smaller than the Immunoglobulin peak. Looking at the fitted curves, the peak temperatures $\mathrm{Tm}$ ( $\mathrm{T}$ middle) and at the enthalpy (total area under the peak) show another difference, the peak temperature of the peaks of the cancer patient serum is $2 \sim 3$ ${ }^{\circ} \mathrm{C}$ higher than for the healthy control serum. Also the enthalpy of the cancer patient serum is significantly reduced. It is known that the albumin protein level decreases at certain types of cancer [9-10], but because the serum is normalized to $26.7 \mu \mathrm{g} / \mu \mathrm{l}$ the decrease in enthalpy is unexpected. It could be speculated that the circulating cancer-related proteins bind to the larger Albumin and Immunoglobulin proteins [2] what causes a shift in temperature and a decrease in enthalpy in the kidney cancer patient serum.

Tab. 2: Measurement results of healthy control blood serum and kidney cancer patient serum.

\begin{tabular}{|c|c|c|c|}
\hline $\begin{array}{c}\text { Serum } \\
\text { sample }\end{array}$ & $\begin{array}{c}\text { Tm curve 1 } \\
\left({ }^{\circ} \mathrm{C}\right)\end{array}$ & $\begin{array}{c}\text { Tm curve 2 } \\
\left({ }^{\circ} \mathrm{C}\right)\end{array}$ & $\begin{array}{c}\text { Enthalpy } \\
(\mu \mathrm{J})\end{array}$ \\
\hline Control 1 & 63.6 & 84.1 & 24.4 \\
\hline Control 2 & 64.6 & 86.8 & 21.3 \\
\hline Patient 1 & 65.8 & 89.1 & 16.1 \\
\hline Patient 2 & 65.8 & 88.4 & 11.0 \\
\hline
\end{tabular}

\section{Conclusions}

The new FLDSC sensor based on the XI-468B chip gives accurate and better results with measurements with serum compared to the FLDSC sensor based on the XI-400 chip. This trial study shows that clear differences can be found in peak temperature and peak enthalpy between serum from healthy control serum and serum from CCRCC diagnosed cancer patients.

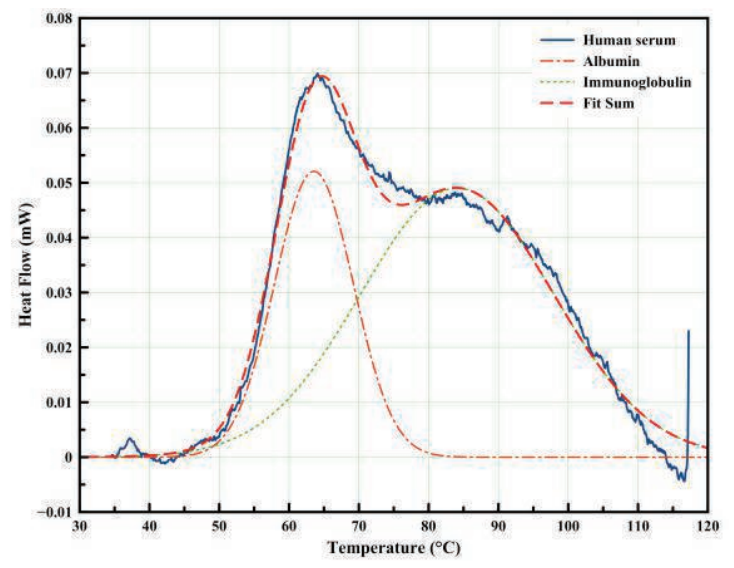

Fig. 6. FLDSC thermogram of a measurement of healthy control blood serum, curve fitted with two curves representing the proteins Albumin and Immunoglobulin. 


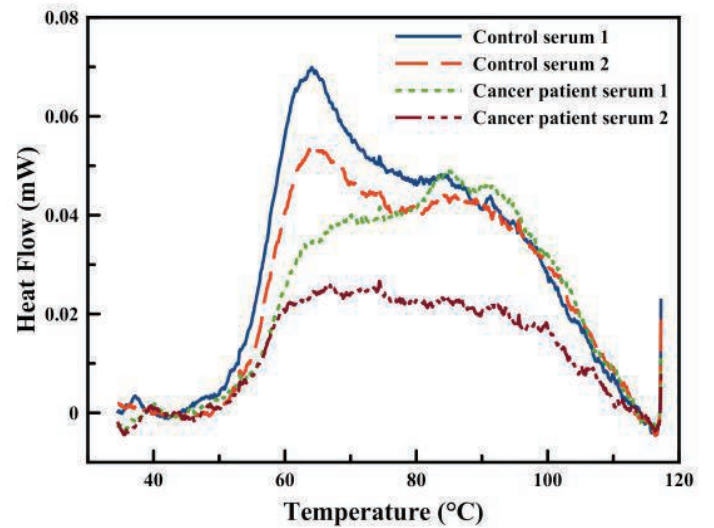

Fig. 7. FLDSC thermogram of blood serum measurements of healthy control samples and blood serum measurements of kidney cancer patients.

\section{Acknowledgements}

The authors gratefully acknowledges the help of the technical staff of Xensor Integration and Institute of Virology, Slovak Academy of Sciences. This project is a part of the EU Marie Curie Initial Training Networks (ITN) Biomedical engineering for cancer and brain disease diagnosis and therapy development: EngCaBra. Project no. PITN-GA-2010-264417.

\section{References}

[1] C. Garbett, J. Miller, B. Jenson and B. Chaires, "Calorimetry Outside the Box: A New Window into the Plasma Proteome", Biophysical Journal, 94 (2008) 1377-1383

[2] Nichola C. Garbett, Chongkham S. Mekmaysy, C. William Helm, A. Bennett Jenson, Jonathan B. Chaires, "Differential scanning calorimetry of blood plasma for clinical diagnosis and monitoring", Experimental and Molecular Pathology, 86 (2009) 186-191 doi:10.1016/j.yexmp.2008.12.001

[3] T. Fekecs, I. Zapf, A. Ferencz and D. Lõrinczy, "Differential scanning Calorimetry (DSC) analysis of human plasma in meloma patients with or without regional lymph node mestastases", J Therm Anal Calorim, 108 (2012) 149-152

[4] R. Splinter, A.W. van Herwaarden, A. Pfreundt, W.E. Svendsen, D. Istrate, W. van Eijk, "Fast Liquid Differential Scanning Calorimetry (FLDSC)", The Online Journal of Scientific Posters ISSN 1754-1417 EP12141

[5] R. Splinter, A.W. van Herwaarden, I.A. van Wetten, A. Pfreundt, W.E. Svendsen, "Fast Differential Scanning Calorimetry of Liquid Samples with Chips", Thermochimica Acta, (2014) doi:10.1016/j.tca.2014.07.013

[6] www.mt.com
[7] T. Collins, S. D'Amico, D. Georlette, J. Claude Marx, A.L. Huston, G. Feller, "A nondetergent sulfobetaine prevents protein aggregation in microcalorimetric studies", Analytical Biochemistry 352 (2006) 299-301 doi:10.1016/j.ab.2006.01.035

[8] R. Splinter, A.W. van Herwaarden, D. Linders, T. Korse, D. van den Broek, M. Bunning, F.K. Uhlenbrock, "Fast Liquid Differential Scanning Calorimetry on human serum", Poster presentation at ESTAC11 Espoo, Finland, August 2014

[9] H. Iwamoto, T. Masago, S. Morizane, A. Yao, T. Isoyama, H. Kadowaki, A. Takenaka, "Low preoperative levels of serum albumin predict lymph node metastases and ultimately correlate with a biochemical recurrence of prostate cancer in radical prostatectomy patients" Cent European J Urol. 66(2013) 126-132 doi:10.5173/ceju.2013.02.art3

[10] S. Dalia, J. Chavez, B. Little, C. Bello, K. Fisher, J.H. Lee, P. Chervenick, L. Sokol, E. Sotomayor, B. Shah, "Serum albumin retains independent prognostic significance in diffuse large B-cell lymphoma in the post-rituximab era", Ann Hematol. 93(2014) 1305-1312 doi:10.1007/s00277-014-2031-2 